\title{
Parallel Hybrid Car Power System Design and Optimization
}

\author{
Huang zhonghua ${ }^{1, a}, X^{2, b}$ ya $^{2, b}$ \\ ${ }^{1}$ Hunan Institute of Engineering, Cooperative Innovation Center of Wind Power Equipment and \\ Energy Conversion, Xiangtan 411104, china \\ ${ }^{2}$ Hunan Institute of Engineering, School of computer and communication, Xiangtan 411104, china \\ acsu707@163.com, bcsu_xieya@163.com
}

\section{Keywords: Hybrid car; Power system design; Performance Simulation; Optimization.}

Abstract: Structure and working principle of parallel hybrid car power system were introduced. Design method of power system parts, such as engine, motor, gearbox and battery pack were proposed. A parallel hybrid car power system design was introduced as an example. Power system performance simulation model based on ADVISOR was established. Accelerating ability, gradeability and driving range of the car were simulated. Simulation results show that power system performance indexes meet design requirements. The design method is feasible. Optimization design of SOC working range of battery pack were finished. Research results show when lower limit of SOC is 0.4 and upper limit of SOC is 0.79 , battery pack has optimal comprehensive performance.

\section{Introduction}

A lot of fuel car using was important cause of urban smog. Compared with fuel cars, gas-electric hybrid car had obvious advantages in reducing emissions and saving fuel consumption. As the government support for new energy cars purchase strength increasing, public awareness of energy conservation and emissions reduction, gas-electric hybrid car were used in the city gradually. Power system performance was an important index to hybrid car. Design method of power system are important research content of hybrid car [1,2]. Power system parameters matching test design was a reliable method with characters of long cycle and high cost. To get power system working performance with simulation had become a trend of power system design research $[3,4,5]$.

According to design requirement of hybrid car's accelerating ability, gradeability, driving range in hybrid drive model and pure electricity drive model, power system parts design method, such as engine, motor, gearbox and battery pack, were proposed. Power system performance simulation model based on ADVISOR was established to validate design method. At the same time, based on power system performance simulation model, optimization design of SOC woring range of battery pack were carried out.

Parallel hybrid car power system structure researched in this paper was shown in Fig. 1, engine, ISG motor were connected with gearbox through velocity torque sensor, battery pack was connected with ISG motor. The power system could work in hybrid drive model and pure electric drive mode. In hybrid model, load was driven by engine and ISG motor simultanenous.In pure electric drive mode, load was driven by ISG motor alone, and engine was in a stall condition.

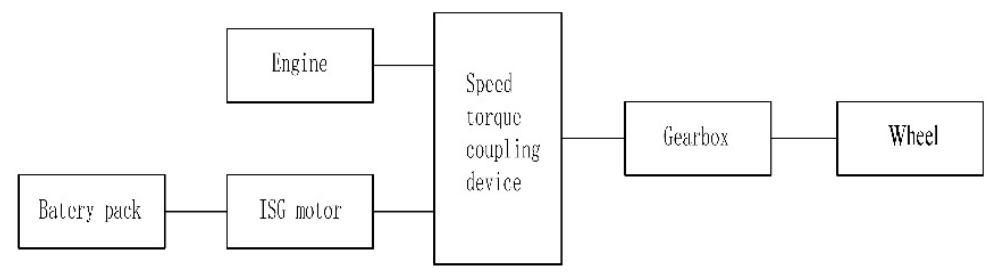

Fig.1 Parallel hybrid car power system structure

\section{Hybrid power system design method}

According to parallel hybrid power system structure shown in Fig 1, hybrid power system design principles were determined as follows. Power system output power must great than total load power 
during the whole drving process. Considering power system had two working models, hybrid power system design were divided into 5 steps.

Step 1 . To calculate ISG motor parameters, battery pack capacity and power according to hybrid car dynamic performance indexes in pure electricity drive model.

Step 2. To calculate engine parameters according to hybrid car dynamic performance indexes in hybrid drive model.

Step 3. To calculate gearbox parameters according to hybrid car dynamic performance indexes.

Step 4. To validate power system parts design results with simulation method.

Step 5. If design results didn't meet design requirement, returen to step 1 and adjust parts paremeters again.

In this paper, hybrid car dynamic performance indexes including maximun driving velocity, acceleration time of $0 \sim 100 \mathrm{~km} / \mathrm{h}$, equivalent fuel consumption per hundred kilometers, maximum gradeability in hybrid drive model; maximun driving velocity, acceleration time of $0 \sim 60 \mathrm{~km} / \mathrm{h}$, maximum gradeability, maximum driving range in pure electric drive model.

\section{ISG motor parameters design method}

When car was in pure electric drive model and driving at maximum velocity $v_{\mathrm{m}}$, the required power $P_{1}$ of the car is following

$$
P_{1}=\frac{v_{m}}{3600 \eta}\left(m g f+\frac{C_{D} A}{21.15} v_{m}^{2}\right)
$$

While, $v_{\mathrm{m}}$ is maximun velocity of car in pure electric drive model, unit is $m / s, m$ is car mass, unit is $\mathrm{kg}, \mathrm{g}$ is acceleration of gravity, unit is $\mathrm{m} / \mathrm{s}^{2}, f$ is rolling resistance coefficient, $C_{\mathrm{d}}$ is Air resistance coefficient, $\eta$ is gearbox efficiency, $A$ is windward area, unit is $m^{2}$ 。

When car was in pure electric drive model, driving with velocity $v_{\mathrm{p}}$ on slope with maximum gradeability $\alpha_{m}$, the required power $P_{2}$ of the car is following

$$
P_{2}=\frac{v_{p}}{3600 \eta}\left(m g f \cos \alpha_{m}+m g \sin \alpha_{m}\right)
$$

While, $v_{\mathrm{p}}$ is climbing velocity, unit is $m / s, \quad \alpha_{m}$ is maximum gradient in pure electric drive model. When car was in pure electric drive model, velocity is increased from 0 to $v_{\mathrm{a}}$, the required power $P_{3}$ of the car is following

$$
P_{3}=\frac{1}{3600 \eta t_{a}}\left(\frac{t_{a} m g f v_{a}}{1.5}+\frac{C_{D} A t_{a}}{52.875} v_{a}^{3}+\frac{m \delta v_{a}^{2}}{7.2}\right)
$$

While, $v_{\mathrm{a}}$ is acceleration end velocity, unit is $\mathrm{m} / \mathrm{s}, \delta$ is car mass conversion factor, $t_{\mathrm{a}}$ is time of acceleration, unit is $s$.

ISG motor maximun power $P_{\mathrm{m}}$ is following

$$
P_{m}=\max \left(P_{1}, P_{2}, P_{3}\right)
$$

ISG motor rated power $P_{\mathrm{e}}$ is following

$$
P_{e}=\max \left(P_{1}, P_{2}\right)
$$

ISG motor rated velocity $n_{\mathrm{e}}$ is following

$$
n_{e}=\frac{n_{\max }}{\beta}
$$

While, $n_{\max }$ is ISG motor maximum velocity, $\beta$ is constant power cofficient.

ISG motor rated torque $T_{\mathrm{e}}$ is following

$$
T_{e}=9550 \frac{P_{e}}{n_{e}}
$$

\section{Engine parameters design method}

When car is in hybrid drive model and driving at maximum velocity $v_{\mathrm{mh}}$, calculation method of car required power $P_{1 \mathrm{~h}}$ is following 


$$
P_{1 h}=\frac{v_{m h}}{3600 \eta}\left(m g f+\frac{C_{D} A}{21.15} v_{m h}^{2}\right)
$$

While, $v_{\mathrm{mh}}$ is maximun velocity of car in hybrid drive model, unit is $\mathrm{m} / \mathrm{s}$.

When car is in hybrid drive model, driving with velocity $v_{\mathrm{ph}}$ on slope with maximum gradeability $\alpha_{m h}$, calculation method of car required power $P_{2 \mathrm{~h}}$ is following

$$
P_{2 \mathrm{~h}}=\frac{v_{p h}}{3600 \eta}\left(m g f \cos \alpha_{m h}+m g \sin \alpha_{m h}\right)
$$

While, $v_{\mathrm{ph}}$ is climbing velocity, unit is $m / s, \alpha_{m h}$ is maximum gradient in hybrid drive model. When car is in hybrid drive model, velocity is increased from 0 to $v_{\text {ah }}$, calculation method of car required power $P_{3 \mathrm{~h}}$ is following

$$
P_{3 h}=\frac{1}{3600 \eta t_{a h}}\left(\frac{t_{a h} m g f v_{a h}}{1.5}+\frac{C_{D} A t_{a h}}{52.875} v_{a h}^{3}+\frac{m \delta v_{a h}^{2}}{7.2}\right)
$$

While, $v_{\text {ah }}$ is acceleration end velocity, unit is $m / s, t_{\text {ah }}$ is time of acceleration, unit is $s$.

Calculation method of engine maximum power $P_{\mathrm{dm}}$ is following

$$
P_{d m}=\max \left(P_{1 h}, P_{2 h}, P_{3 h}\right)
$$

Calculation method of engine rated power $P_{\mathrm{de}}$ is following

$$
P_{d e}=\max \left(P_{1 h}, P_{2 h}\right)-P_{e}
$$

\section{Gearbox parameters design}

Velocity range of ISG motor is great than engine in hybrid power system. Gearbox is needed to match ISG motor velocity and engine velocity. Gearbox ratio $i$ is a main parameter, which is mainly depend on car maximum driving velocity and engine maximum ratation velocity. Minimum gearbox ratio $i_{\min }$ is needed in hybrid drive mode. $i_{\max }$ is decided by engine maximum driving velocity.

Calculation method of $i_{\min }$ is following

$$
i_{\min } \geq 0.377 r \frac{n_{d \max }}{v_{m h}}
$$

While, $r$ is car wheel radius, unit is $m, n_{\mathrm{dmax}}$ is engine maximum rotation velocity, unit is $r / \mathrm{min}$. Maxmum gearbox ratio $i_{\max }$ is needed in pure electric drive mode, and car is in a state of crawling slope with maximum gradient. Calculation method of $i_{\max }$ is following

$$
i_{\max } \leq \frac{1}{T_{e} \eta}\left[\operatorname{mgr}\left(f \cos \alpha_{m}+\sin \alpha_{m}\right)+\frac{C A v_{p}^{2}}{21.15}\right]
$$

\section{Battery pack parameters design method}

Main design parameters of battery pack are power and energy. The requirement of power and energy are different in pure electric drive model and hybrid drive model. In pure electric drive model, battery pack power need to meet the requirements maximum load power, and battery pack energy need to meet the requirements of driving range. In hybrid mode, battery pack power need to great than the difference value between maximum load power and engine output power, and battery pack power energy need to meet the requirements of car surplus energy efficient recycling.

Calculation method of $P_{\mathrm{b}}$ is following

$$
P_{\mathrm{b}}=P_{\mathrm{e}}+P_{\mathrm{a}}
$$

While, $P_{a}$ is car attachment required power, unit is KW.

When car driving range is $L$ with constant velocity $v_{\mathrm{e}}$, Calculation method of required power $W$ is following

$$
W=\frac{L P_{1}}{\mathrm{v}_{\mathrm{e}}}
$$

While, $L$ is rated driving range, unit is $\mathrm{km}$.

Calculation method of number of single cell $N$ is following 


$$
N=\frac{\eta_{\mathrm{e}} E C}{1000 W}
$$

While, $E$ is working voltage of single cell, unit is $\mathrm{V}, C$ is single cell battery capacity, unit is Ah, $\eta_{e}$ is depth of discharge of battery.

\section{Power system design example}

Power system parts design of a hybird car were introduce as design example. Hybrid car basic parameters were shown in Table.1, corresponding hybrid car dynamic performance indexes were shown in Table. 2.

Table.1 Hybrid car basic parameters

\begin{tabular}{|c|c|c|c|}
\hline parameters（unit） & value & $\begin{array}{c}\text { parameters } \\
\text { (unit) }\end{array}$ & value \\
\hline car mass (kg) & 1200 & $\begin{array}{l}\text { gearbox } \\
\text { efficiency }\end{array}$ & 0.91 \\
\hline rated load (kg) & 160 & $\begin{array}{l}\text { wheel radius } \\
\text { (m) }\end{array}$ & 0.305 \\
\hline $\begin{array}{l}\text { air drag } \\
\text { coefficient }\end{array}$ & 0.30 & $\begin{array}{l}\text { windward area } \\
\left(\mathrm{m}^{2}\right)\end{array}$ & 2.02 \\
\hline $\begin{array}{l}\text { height of mass } \\
\text { center }(\mathrm{m})\end{array}$ & 0.40 & wheelbase (m) & 2.65 \\
\hline $\begin{array}{l}\text { rolling resistance } \\
\text { coefficient }\end{array}$ & 0.02 & $\begin{array}{l}\text { mass conversion } \\
\text { coefficient }\end{array}$ & 1.05 \\
\hline
\end{tabular}

Table.2 Dynamic performance indexes

\begin{tabular}{lclc}
\hline \multicolumn{1}{c}{ Hybrid drive } & \multicolumn{2}{c}{ Pure electric drive } \\
\hline $\begin{array}{l}\text { parameters (unit) } \\
\text { maximum driving } \\
\text { velocity }(\mathrm{km} / \mathrm{h})\end{array}$ & $>160$ & $\begin{array}{l}\text { parameters ( unit) } \\
\text { maximum driving } \\
\text { velocity }(\mathrm{km} / \mathrm{h})\end{array}$ & $>120$ \\
$\begin{array}{l}\text { maximum } \\
\text { gradeability }(\%)\end{array}$ & $>25$ & $\begin{array}{l}\text { maximum } \\
\text { gradeability }(\%)\end{array}$ & $>20$ \\
$\begin{array}{l}0 \sim 100 \mathrm{~km} / \mathrm{h} \\
\text { acceration time (s) }\end{array}$ & $<9$ & $\begin{array}{l}0 \sim 60 \mathrm{~km} / \mathrm{h} \\
\text { acceration time } \\
(\mathrm{s})\end{array}$ & $<6$ \\
$\begin{array}{l}\text { fuel consumption } \\
\text { of } 100 \mathrm{~km}(\mathrm{~L})\end{array}$ & $<6$ & range $(\mathrm{km})$ & $>50$ \\
\hline
\end{tabular}

In this paper, $n_{\max }=5000 \mathrm{r} / \mathrm{m}, n_{d \max }=5000 \mathrm{r} / \mathrm{m}, v_{\mathrm{p}}=40 \mathrm{~km} / \mathrm{h}, v_{\mathrm{ph}}=60 \mathrm{~km} / \mathrm{h}, \mathrm{L}=50 \mathrm{~km}, P \mathrm{a}=3 \mathrm{KW}$, gears of gearbox are 5 shifts. Combined with parameters shown in Table.1 and Table.2, power system parts were calculated with Eq.1 $\sim$ Eq.17. Power system parts calculation results were shown in Table.3.

Table.3 Calculation results

\begin{tabular}{|c|c|c|}
\hline Name & param & \\
\hline \multirow{3}{*}{ engine } & maximum output power $(\mathrm{KW})$ & 62 \\
\hline & maximum output velocity (rpm) & 5000 \\
\hline & maximum output power (KW) & 42 \\
\hline \multirow[t]{2}{*}{ ISG motor } & rated output power $(\mathrm{KW})$ & 17 \\
\hline & rated velocity (rpm) & 1250 \\
\hline \multirow{2}{*}{ battery pack } & battery capacity (Ah) & 45 \\
\hline & baterrry cell numbers & 25 \\
\hline \multirow{2}{*}{ gearbox } & number of gears & 5 \\
\hline & gear ratio $\left(i_{1} \sim i_{5}\right)$ & $\begin{array}{lllll}4.1, & 4.8, & 5.6, & 6.6,7.7\end{array}$ \\
\hline
\end{tabular}

\section{Power system performance simulation}

Simulation research were carried out to validate the designe results. The simulation software was ADVISOR2002, which was developed by USA renewable energy laboratory. As a mature simulation software of car power system design, ADVISOR had been widely used in car power system design[6,7]. In hybrid drive mode, simulation content covers maximum drving velocity of car, acceleration time of $0 \sim 100 \mathrm{~km} / \mathrm{h}$ and maximum gradability at velocity of $40 \mathrm{~km} / \mathrm{h}$. In pure electric drive mode, simulation content covers maximum drving velocity of car, acceleration time of 0 to 60 $\mathrm{km} / \mathrm{h}$, maximum gradability at velocity of $30 \mathrm{~km} / \mathrm{h}$, maximum drving range.

In ADVISOR, simulation parameters setting covers car mass, driving cycles, gradability performance testing and acceleration performance testing. Car parameters setting covers car, ISG motor, battery pack, gearbox and wheel/axle.There were three typical cycles in ADVISOR software. CYC_UDDS cycles were used in this paper considering generality, velocity curve of CYC_UDDS cycles was 
shown in Fig.2, driving time was 1369s, driving distance was $11.99 \mathrm{~km}$, maximum drving velocity was $91.25 \mathrm{~km} / \mathrm{h}$, average drving velocity was $31.51 \mathrm{~km} / \mathrm{h}$.

Hybrid power system performance simulation were carried out based on the simulation model. Vehilce dynamic performance simulation result in hybrid drive model are as follows: Gearbox gear working curve is shown in Fig.3, which shows that gear are changed with car drving velocity changing. It shows gearbox working status is normal. Car acceration time of $0 \sim 100 \mathrm{~km} / \mathrm{h}$ is $8.4 \mathrm{~s}$, equivalent fuel consumption of $100 \mathrm{~km}$ is $4.3 \mathrm{~L}$, maximum gradeability is $35 \%$, maximum drving velocity is $200 \mathrm{~km} / \mathrm{h}$.

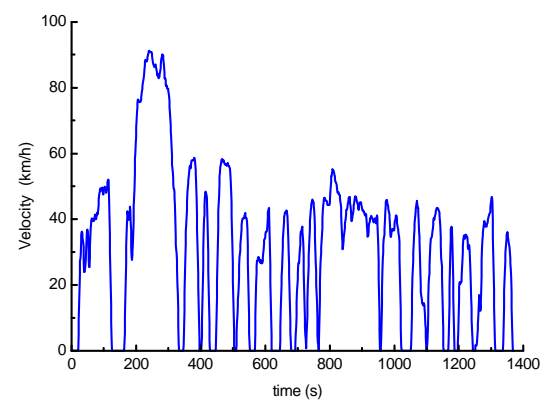

Fig.2 Velocity curve

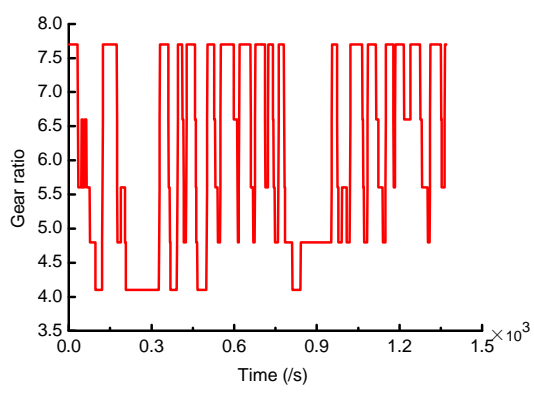

Fig.3 Gearbox shift curve

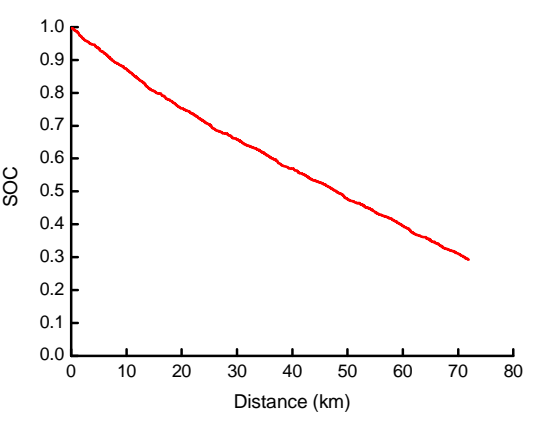

Fig. 4 Driving range simulation curve

During simulation, in order to protect battery pack life, lower limit of battery pack SOC is set as 0.3. Hybrid car dynamic performance simulation results in pure electric drive model are as follows: acceration time of $0 \sim 60 \mathrm{~km} / \mathrm{h}$ is $4.4 \mathrm{~s}$, maximum gradeability is $25 \%$, maximum drving velocity is $150 \mathrm{~km} / \mathrm{h}$. Hybrid car driving range curve is shown in Fig.4, it shows that driving range of the hybrid car is about $70 \mathrm{~km}$, which is great than design indexes.

Contrast with dynamic performance indexes in Table.2, it shows that hybrid car power system parts design results can meet design requirement. It means power system parts design method proposed in this paper are reasonable.

\section{SOC working range optimization}

SOC working range was a important parameter to battery pack. To increase SOC working range was benefit to decrease engine fuel consumption, but was harmful to battery pack working life. So, it was very important for battery pack to set reasonable SOC working range.

Simulation research on SOC working range with engine fuel consumption and battery pack working life were carried out. In simulation model, lower limit of SOC was defined as SOC_lo, upper limit of SOC was defined as SOC_hi. Considering battery pack working requirement, SOC_lo was set as 0.4 0.6, SOC_hi was set as 0.65 0.85. the relationship between engine fuel consumption with SOC_lo and SOC_hi were simulated.

The relationship between engine fuel consumption with SOC_lo was shown in Fig 5, which shows that engine fuel consumption is decreased with SOC_lo increasing. The relationship between engine fuel consumption with SOC_hi was shown in Fig 6, which shows that engine fuel consumption is increased with SOC_hi increasing.

In order to obtain mathmatic relationship between engine fuel consumption with SOC_lo and SOC_hi. Curves of Fig. 5 and Fig. 6 were fitted. Define $x_{1}$ as SOC_lo, $x_{2}$ as SOC_hi, $y_{1}$ as fuel consumption corresponding with $x_{1}, y_{2}$ as fuel consumption corresponding with $x_{2}$. Curve fitting results of Fig.5 is as follows

$$
y_{1}=-1.1299 * x_{1} \wedge 2-1.2538 * x_{1}+5.2908
$$

Curve fitting results of Fig. 6 is as follows

$$
y_{2}=29.5448 * x_{2} \wedge 2-39.0158 * x_{2}+17.0105
$$

In order to obtain optimization value of SOC working range, optimization index of $y$ was defined was follows

$$
y=k^{*} y_{1}+(1-k)^{*} y_{2}
$$


While, $k$ was coffeicient. In this paper, according to battery pack using experiences, $k$ was set as 0.4. So, optimization object was to obtain maximun value of $y$.

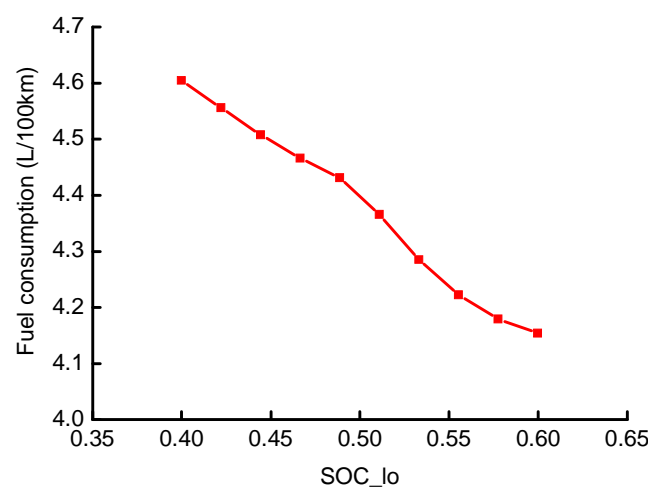

Fig. 5 Fuel consumption with SOC_lo

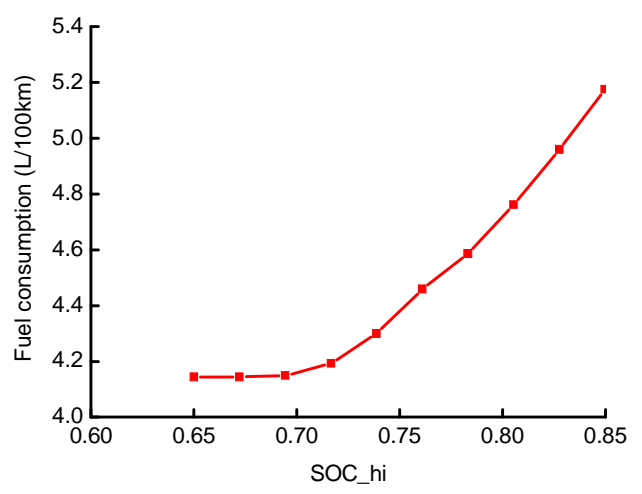

Fig. 6 Fuel consumption with SOC_hi

Maximun value of $y$ was obtained with parameter optimization method. Optimization results are as follows: maximum value of $y$ is 1.1104 , when $x_{1}=0.4$ and $x_{2}=0.79$. so, optimal SOC working range of battery pack is SOC_lo $=0.4$, SOC_hi $=0.79$.

\section{Conclusions}

A kind of hybrid power system design method was proposed, simulation results shows that the method is suitable for parallel hybrid power system parts design.

Optimization design of SOC woring range of battery pack were finished. research results shows when SOC_lo $=0.4$ and SOC_hi=0.79, battery pack has optimal comprehensive performance.

\section{Acknowledgements}

This work was financially supported by Project by Hunan Provincial Natural Science Foundation of China (14JJ5006); Aid program for Science and Technology Innovative Research Team in Higher Educational Institutions of Hunan Province.

\section{References}

[1] Wei Liu, Hongwen He, Zexing Wang. A Comparison Study of Energy Management for A Plug-in Serial Hybrid Electric Vehicle. Energy Procedia, Vol.88 (2016), p.854-859

[2] Martin Mruzek, Igor Gajdáč, Luboš Kučera, et. al. Analysis of Parameters Influencing Electric Vehicle Range. Procedia Engineering, Vol.134 (2016), p. 165-174

[3] H. Pfluegl, F. Diwoky, B. Brunnsteiner, et.al. ASTERICS - advanced simulation models and accelerated testing for the development of electric vehicles. Transportation Research Procedia, Vol.14 (2016), p. 3641-3650

[4] Pan er-dong, Shen jiang-wei, Xiao ren-xin. Research of the parameters matching of paraller PHEV based on ADVISOR. New Technology and New Process, No.1 (2016), p.70-74

[5] Huang Zhonghua, Xie Ya, Deng Yi. Hybrid Excavator Shafting Torsional Vibration Analysis. Applied Mechanics and Materials, Vol.268-270 (2013),.p 1262-1265

[6] Zhang Qi.Simulation and Research of Electric Vehicle's Dynamic Performance Based on ADVISOR. Agricultural Equipment \& Vehicle Engineering, No.1 (2012), p. 31-33

[7] Hu Minghui, Xie Hongjun, Qin Datong. A Study on the Parameter Matching Between the Motor and Transmission System of an Electric Vehicle. Automotive Engineering, No.12 (2013), p. $1068-1073$ 